\title{
Editorial Note: Multi-Task Learning
}

Published online: 14 September 2018

(C) Springer Science+Business Media, LLC, part of Springer Nature 2018

Multimedia Tools and Applications gratefully acknowledges the editorial work of the scholars listed below on the special issue entitled, "Multi-Task Learning."

Of 29 papers submitted to this issue, 14 were eventually accepted after a stringent peerreview process.

Dr. Yingying Zhu (Corresponding Guest Editor)

The University of North Carolina at Chapel Hill, Chapel Hill, NC, USA

zyy@med.unc.edu

Dr. Shichao Zhang

Guangxi Normal University, Guangxi, China

zhangsc@mailbox.gxnu.edu.cn

Publisher's Note Springer Nature remains neutral with regard to jurisdictional claims in published maps and institutional affiliations. 